\title{
GESTÃO DA INOVAÇÃO, DESENVOLVIMENTO E DIFUSÃO DE VEÍCULOS HÍBRIDOS E ELÉTRICOS MITIGADORES DA POLUIÇÃO URBANA: UM ESTUDO DE CASO MÚLTIPLO
}

\author{
Isabela Grespan da Rocha Teixeira \\ Mestranda em Administração de Organizações na FEA-RP - USP \\ Especialista em Gestão de Comércio Exterior e Negócios Internacionais pela Fundação Getúlio Vargas \\ - FGV \\ Pesquisadora do Centro de Pesquisa e Projetos em Marketing \& Estratégia - MARKESTRAT \\ isabela.grteixeira@gmail.com (Brasil)
}

\section{Rogério Ceravolo Calia}

Doutor em Administração de Empresas pela Fundação Getúlio Vargas - FGV

Professor em R.D.I.D.P da Universidade de São Paulo - USP

calia@fearp.usp.br (Brasil)

\section{RESUMO}

Estudos indicam que o aumento no uso de combustíveis fósseis e no uso da terra eleva o nível de dióxido de carbono $\left(\mathrm{CO}_{2}\right)$ e com isso, alteram o ecossistema contribuindo para o aquecimento global. Nesse sentido, é preciso estimular a pesquisa e disseminar produtos inovadores que visem à melhoria da eficiência energética e a mitigação das emissões dos gases que contribuem para o efeito estufa. Para isso, foi desenvolvido um estudo de caso múltiplo com cinco empresas brasileiras montadoras e revendedoras de veículos com o objetivo de entender como ocorre a inovação, o desenvolvimento e a difusão de produtos mitigadores da poluição no segmento de veículos elétricos e híbridos para transporte individual ou coletivo. Como resposta ao estudo, verificou-se que o mercado para veículos elétricos e híbridos, tanto na forma coletiva como na forma individual, no Brasil ainda é pequeno, embora esteja em fase de expansão. Das empresas estudadas apenas uma desenvolveu o seu produto para atender o mercado. As demais colocaram os seus produtos para comercialização e agora estão migrando para uma nova forma de atender os clientes, desenvolvendo adaptações para difundir o produto no mercado brasileiro.

Palavras-chave: Mitigação de $\mathrm{CO}_{2}$, veículos elétricos, veículos híbridos, difusão da inovação, gestão da inovação. 


\section{INTRODUÇÃO}

Nos últimos anos, as preocupações relacionadas às mudanças climáticas, que podem ocorrer por ações antropogênicas e naturais, têm aumentado. Estudos indicam que o equilíbrio energético tem sofrido interferência de uma combinação de fatores como aumento na emissão de gases de efeito estufa (GEE), de aerossóis e também da radiação solar. Esse aumento é consequência do maior uso de combustíveis fósseis e da terra, que elevam o nível de dióxido de carbono $\left(\mathrm{CO}_{2}\right)$ além do aumento das emissões de metano $\left(\mathrm{CH}_{4}\right)$ e oxido nitroso $\left(\mathrm{N}_{2} \mathrm{O}\right)$ gerados, em sua maioria, pela agricultura e pecuária. Todos esses fatores levam a alterações no ecossistema que contribuem para o aquecimento global e como consequência diminuição das calotas polares, aumento do nível do mar, ocorrência de eventos climáticos extremos, aumento de atividades de ciclones, secas intensas e chuvas torrenciais que alagam extensas áreas e provocam destruição. Assim, é preciso estimular e disseminar políticas que visem à melhoria da eficiência energética e a mitigação das emissões dos gases que contribuem para o efeito estufa Intergovernmental Panel on Climate Change [IPCC] (2007).

Além das alterações climáticas, os gases de efeito estufa interferem na qualidade da saúde humana de diferentes modos. Como exemplo a Organização Mundial da Saúde cita alteração da distribuição geográfica e sazonalidade de certas doenças infecciosas, perturbação dos ecossistemas produtores de alimentos e aumento da frequência de eventos climáticos extremos, como furacões World Health Organization [WHO] (2011). As estatísticas indicam que por ano aproximadamente 800.000 pessoas morrem por causas atribuídas à poluição do ar, 1,8 milhões de diarreia devido à falta de acesso a água potável e a saneamento básico e 60.000 em desastres naturais. Nesse sentido, as alterações climáticas trazem grandes desafios no controle de doenças infecciosas (WHO, 2008). De acordo com um estudo feito pelo Centro de estudos em Sustentabilidade da Fundação Getúlio Vargas [GVCES] e o Programa das Nações Unidas para o Meio Ambiente [PNUMA] (2011) a população de menor renda, que compõe a base da pirâmide, é a que mais sofrerá com as mudanças no clima. Assim, recomenda-se o foco em novos produtos para agropecuária, segurança hídrica e planejamento urbano (GVCES \& PNUMA, 2011).

Frente ao contexto apresentado, estudar as empresas, seu processo de inovação, a forma de difusão das novas tecnologias, pode trazer informações importantes para a sociedade e outras empresas que queiram diminuir o resultado de suas ações no ambiente.

Revista de Administração e Inovação, São Paulo, v. 10, n.2, p.199-218, abr./jun. 2013. 
Diante do exposto, este artigo apresenta um estudo de caso múltiplo com o objetivo de entender como a inovação para o desenvolvimento de produtos contribui para a definição do modelo de negócio, e a partir disso descrever as redes de difusão da inovação das empresas estudadas. Com este estudo, buscou-se responder às seguintes perguntas:

-Como é o processo de inovação de uma empresa que fabrica e comercializa um produto que melhora a eficiência e que reduz a poluição causada por veículos?

-Como é a natureza e os desenvolvimentos dos seus relacionamentos colaborativos?

\section{REVISÃO DA LITERATURA}

\subsection{Transporte: o impacto no aquecimento global e nas mudanças climáticas}

A queima de combustíveis por fontes móveis agrava o problema da poluição atmosférica em quase todas as grandes cidades e representa um sério problema ambiental, especialmente quando se fala em países desenvolvidos. Essa poluição é causada por diferentes processos antropogênicos gerados por usinas de energia, indústrias, comércio, queima de combustível doméstico, circulação de veículos automotores, sendo que estes últimos estão entre os que mais contribuem para agravar o problema. (Mayer, 1999). Diante disso, vem crescendo a preocupação acerca dos possíveis efeitos adversos causados à saúde pela poluição do ar. No Brasil, estudos encontraram associações significativas entre poluição do ar e hospitalizações em crianças e adultos por problemas respiratórios e também relacionados à mortalidade infantil e em idosos (Gouveia et al., 2003).

A poluição ambiental interfere nas mudanças climáticas e assim causa diversos impactos na saúde humana. Estes impactos estão relacionados ao aumento na ocorrência de temperaturas extremas, aumento no nível do mar e aumento na disseminação de doenças contagiosas (WHO, 2009). Estima-se que as mudanças climáticas trarão implicações para a saúde pública, especialmente em países em desenvolvimento, ilhas, cidades costeiras e para a população mais carente. Para redução destes impactos é necessário formulação de políticas, investimentos financeiros e colaboração multisetorial (Kumaresan, Narain, \& Sathiakumar, 2010). Nesse sentido, o IPCC (2007) grupo três (3) de mitigação, apresenta várias práticas por setor, como suprimento de energia, construções, indústria, agricultura, florestas e transporte. No caso deste último, objeto de estudo do presente artigo, o IPCC (2007) sugere como alternativas de tecnologia disponível o uso veículos com combustíveis mais eficientes, veículos híbridos, biocombustíveis, eficiência de combustíveis para a aviação, mudança do modal rodoviário Revista de Administração e Inovação, São Paulo, v. 10, n.2, p. 199-218, abr./jun. 2013. 
para ferroviário, sistemas de transporte público e transporte não motorizado como uso de bicicletas. Desta forma, as empresas do estudo apresentam tecnologia híbrida para transporte coletivo e tecnologia apenas elétrica para transporte individual.

\subsection{Panorama do setor de energia para transporte automotivo e alternativas substitutas}

As questões relacionadas à energia se apresentam cada vez mais estratégicas para os países de todos os continentes. No Brasil, o órgão responsável por definir as diretrizes da política energética nacional é o Ministério de Minas e Energia [MME]. Em seu estudo do Balanço Energético Nacional [BEN], ainda com resultados preliminares ${ }^{1}$, aponta que houve aumento de 10,8\% na demanda de combustíveis de 2010 em relação a 2009. Esse fato deveu-se principalmente ao crescimento da frota veicular nacional, destacando elevação de 41,2\% nas vendas de veículos pesados. Em 2010 a matriz energética brasileira ainda se baseou em energias de fontes não renováveis, representando estas 54,6\% do total de oferta interna de energia. Destes, aproximadamente $38 \%$ são referentes ao uso de petróleo e derivados. Esses dados colocam o setor de transportes como o segundo maior consumidor de energia, ficando atrás apenas do industrial Empresa de Pesquisa Energética [EPE] (2011).

Governos, sociedades e institutos de pesquisas têm concentrado estudos na intenção de melhorar a eficiência energética. A instabilidade nos preços e mercado de petróleo, cenários de guerras e a melhoria da qualidade do ar nas áreas urbanas são os principais motivos (Ribeiro \& Abreu, 2008). Além disso, cada vez mais estudiosos buscam alternativas para redução da emissão de $\mathrm{CO}_{2}$ e outros gazes que contribuem para o aumento do efeito estufa.

No Brasil, existem políticas públicas que visam aumentar a eficiência dos veículos, tanto os novos como os usados, e diversificar a matriz energética pelo incentivo do uso do etanol e biodiesel (Ribeiro \& Abreu, 2008). Há também inovação das tecnologias por parte das indústrias automobilísticas que desenvolvem veículos movidos à eletricidade e híbridos, que misturam eletricidade com outro tipo de combustível, e são conhecidos como ultra low emissions vehicles [ULEV]. Para transporte público coletivo, os ULEV mais conhecidos são os movidos à bateria, os

\footnotetext{
${ }^{1}$ As informações preliminares são publicadas sempre no primeiro semestre posterior ao ano base e a edição de 2011 pode ser acessada em https://ben.epe.gov.br/BENResultadosPreliminares2011.aspx. O Relatório Final do BEN 2011 pode sofrer ajustes de dados devido à revisões empreendidas pelo processo de consolidação das estatísticas energéticas.
}

Revista de Administração e Inovação, São Paulo, v. 10, n.2, p.199-218, abr./jun. 2013. 
trólebus, os de célula combustível (hidrogênio) e os veículos híbridos. Todos eles são silenciosos e mitigam a poluição do meio ambiente. Para transporte individual o mais conhecido é o elétrico com baterias de chumbo ácido ou lítio.

Especificamente para estudos de inovação na área de transporte, Rietveld (2011) apresenta como política de redução de energia e forma de redução dos congestionamentos, o trabalho virtual. Segundo o autor, essa não é uma inovação verde recente, mas que nunca foi amplamente difundida, por algumas razões, entre elas, prioridade dada aos congestionamentos e não ao transporte verde, comportamento conservador dos funcionários e dos departamentos de RH das empresas.

\subsection{Gestão da inovação ambiental}

O mercado cada vez mais competitivo faz com que as empresas busquem por inovação. Francis e Bessant (1995) apontam que a empresa deve pensar em um portfólio estratégico de inovação considerando os 4p's da inovação. Segundo esses autores tem-se inovação em (i) produto, que realiza a mudanças nas "coisas", em (ii) processo, no qual a mudança ocorre no modo de se fazer as coisas, em (iii) posição, onde a mudança é focada no contexto em que produtos e serviços são lançados e por fim, em (iv) paradigma, no qual a mudança ocorre nos modelos mentais subjacentes que orientam o que a empresa faz.

Rothwell (1992) retrata a evolução das formas de inovação classificando-as em cinco gerações. A primeira geração é modelo simples e linear, conhecido como inovação empurrada pela tecnologia, no qual o mercado recebe o que o departamento de P\&D desenvolveu. A segunda busca fazer as inovações baseadas nas necessidades do mercado e torna-se base para a terceira geração de inovação, que é uma combinação entre as duas primeiras. Essa geração caracteriza-se por integrar os departamentos de P\&D e Marketing e olhar tanto para dentro como para fora da empresa. A quarta geração da inovação integra times de diversos departamentos em paralelo com os fornecedores. Por fim, a quinta geração apresenta um modelo mais sofisticado e integrado de redes. Nesse modelo, as inovações acontecem totalmente integradas com consumidores, fornecedores de primeira linha para desenvolvimento conjunto de novos produtos, joint-ventures, grupos de pesquisa colaborativa (Rothwell, 1992). Observa-se que a cada geração da inovação mais atores são integrados no processo de desenvolvimento até chegar num modelo totalmente integrado com diversos elos da cadeia. Nesse sentido, não basta à empresa possuir um departamento de $\mathrm{P} \& \mathrm{D}$ para ter bom desempenho em inovações, ela precisa ter capacidade inovadora como um todo. Moura et al. (2008) em seu estudo de caso, apresenta aprendizados sobre inovação e relacionamento entre os elos da cadeia. Entre eles, Revista de Administração e Inovação, São Paulo, v. 10, n.2, p. 199-218, abr./jun. 2013. 
observou-se que o P\&D pode ocorrer de "fora para dentro", no qual os recursos de uma rede de inovação são interiorizados para a empresa. Assim, a inovação gerou acesso mercadológico e recursos financeiros. Além disso, a inovação adotada viabilizou a obtenção de uma nova tecnologia e um novo produto.

Dessa forma, pode-se dizer que o processo de inovação cria formas de conhecimento, novos produtos, processos, novas formas de trabalho (Neely \& Hii, 1998) e novos processos de gestão. Observa-se também, que a escalada do conhecimento é impulsionada pela inovação, que é fator determinante para a competitividade das nações.

Em um estudo, realizado por Conway e Steward (1998), foi verificado que os atores de uma rede podem influenciar os processos de inovação ambiental de uma empresa foco. Este estudo utilizou parte da rede para a construção do quadro conceitual no qual as inovações investigadas faziam parte da perspectiva da organização em análise. Dessa forma, foram verificados cinco (5) categorias que estimularam a iniciação de projetos de inovação ambiental sendo: (1) regulamentação, (2) ambiente político e cultural, (3) consumidores, (4) pressões de mercado (fornecedores) e por fim, (5) conhecimento (tecnologia) (Conway \& Steward, 1998). De acordo com outro autor, Gulati (1998), as redes podem influenciar na criação e no sucesso dos relacionamentos, sendo um condutor valioso de informação que fornece oportunidades e restrições para as organizações, além de serem importantes para o comportamento e o desempenho das alianças. O conceito de rede de uma empresa engloba a análise do conjunto desses integrantes de forma a permitir mapear os relacionamentos existentes entre eles e avaliar o impacto da concorrência e do ambiente operacional em geral (Neves, 2007). Segundo Gulati (1998), as redes podem ser verticais, entre empresas de diferentes estágios de tecnologia como fornecedores e distribuidores, ou horizontais, que envolve os competidores ou empresas que fornecem produtos complementares ao mesmo mercado alvo. Dessa forma, um dos objetivos dessas alianças é solucionar problemas em comum e fortalecer o crescimento e desenvolvimento das organizações, que podem ser vistos por alguns estudiosos como contraditório ao conceito de sustentabilidade, visto que influenciam o consumo.

O conceito de sustentabilidade é pautado em três pilares: o econômico, o social e o ambiental. Tal conceito foi disseminado por John Elkington em seu livro Cannibals with Forks: The Triple Bottom Line of 21 st Century Business ${ }^{2}$ de 1997. Existe uma linha de teóricos que defendem que os três

${ }^{2}$ Elkington, J. (1997). Cannibal with Forks: The Triple Bottom Line of 21st Century Business. Canada: NSP New Society Publishers.

Revista de Administração e Inovação, São Paulo, v. 10, n.2, p.199-218, abr./jun. 2013. 
pilares não podem ser tratados como equivalentes e apresentam dois motivos. Primeiro, porque a economia é uma instituição que emerge da sociedade, nesse sentido, as regras são criadas pela sociedade para mediar a troca de bens. Com o ambiente é diferente, pois ele não é criado pela sociedade. Segundo, porque o ambiente sustenta a sociedade e a economia. Verifica-se, contudo, que os recursos disponíveis na terra são limitados às atividades humanas (Adams, 2006). Essa limitação de recursos é que torna importante o estudo de novas maneiras para mitigar as ações que prejudicam o meio ambiente, como o transporte de pessoas e cargas.

\subsection{Difusão da Inovação}

Gerar inovação não é suficiente. É preciso disseminar as descobertas para o mercado. Huber (2008) conclui em seu estudo que a governança nacional é preferível à governança global para conduzir progressos no desenvolvimento e difusão das inovações de tecnologia ambiental. O modelo de inovação e difusão acontece por regulamentações pontuais e o desenvolvimento e a implementação de novas tecnologias pode acontecer de duas formas:

(a) em indústrias nacionais ou

(b) em algumas empresas e nações que fazem parte de um contexto inovador, para depois serem adaptadas por outras nações que possuem capacidades para usá-las.

O estudo também constatou que atualmente as nações mais industrializadas buscam construir meios de produção mais inovadores, além de desenvolverem capacidades de pesquisa e desenvolvimento. Outro ponto importante apontado por Huber (2008) é que importantes inovações ambientais, como energias mais limpas e propulsão veicular, levam tempo para serem incorporadas. Esse fato ocorre tanto para países em desenvolvimento como para países desenvolvidos. Yalabic e Fairchild (2011) descobriram que os consumidores, as leis regulamentadoras e a pressão pela competitividade são fatores impulsionadores para geração de inovação ambiental, principalmente para as empresas "sujas", que não possuem produtos e processos que respeitam o meio ambiente. Esses fatores impulsionadores estão empurrando as empresas para um nicho de baixo carbono, no entanto, os efeitos de lucros para as empresas e o bem estar dos consumidores ainda estão longe de se tornarem realidade.

Rogers e Schoemaker (1971) entendem que a inovação pode ser entendida como algo percebido como novo pelo indivíduo e a difusão como o processo pelo qual uma inovação é comunicada ao longo do tempo entre os membros de um sistema social. Jacob et al. (2001) coloca que a difusão de inovações ambientais é facilitada por reduções de custo, pela orientação para exportação e Revista de Administração e Inovação, São Paulo, v. 10, n.2, p. 199-218, abr./jun. 2013. 
pela superioridade da inovação. A maioria das inovações ambientais surge em países de elevada renda para financiar intensivamente o desenvolvimento de inovações.

\section{METODOLOGIA}

O presente trabalho caracteriza-se por um estudo de caso múltiplo conforme aponta Yin (2010). Os projetos de caso múltiplo são variantes da mesma estrutura metodológica e não existe distinção ampla entre o estudo de caso único e múltiplo, podendo esse último ser considerado mais robusto. Então, mesmo que todos os projetos possam resultar em estudos de caso bem sucedidos, quando houver opção de recursos, os projetos de caso múltiplo devem ser preferidos, pois mesmo com dois casos, existe a possibilidade de replicação direta. Dessa forma, esse tipo de estudo deve seguir uma replicação e não uma lógica de amostragem (Yin, 2010). Ainda sobre estudo de caso, Voss, Tsikriktsis e Frohlich (2002), afirmam que as pesquisas com estudos de caso têm alto impacto e podem ajudar a desenvolver novas teorias. Além disso, possuem alta validade e solidez junto aos usuários finais da pesquisa acadêmica aplicada em administração.

Após revisão de literatura, foi elaborado o objetivo da pesquisa visando entender como ocorre a inovação, o desenvolvimento e a difusão de produtos mitigadores da poluição no segmento de veículos elétricos e híbridos para transporte individual ou coletivo. Segundo Yin (2010) o método de estudo de caso permite observar as características holísticas e significativas dos eventos da vida real na qual busca responder às questões "como" e "porque", que são mais explanatórias e levam ao estudo de caso. Segundo Bonoma (1985) o estudo de caso combina métodos para coleta de dados, como entrevistas, questionários, observações e a evidência, que pode ser quantitativa e/ou qualitativa. De acordo com Consoli et al. (2008) foi percebido uma elevada concentração de pesquisas que utilizaram o método com objetivo exploratório e descritivo, geralmente para análises comparativas.

O estudo de caso conta com as mesmas técnicas da pesquisa histórica, no entanto, são adicionadas duas fontes de evidência. Uma delas é a observação direta nos eventos, o que permite analisar uma ampla variedade de evidências. A outra fonte é a entrevista com as pessoas envolvidas nos eventos (Yin, 2010). As entrevistas deste trabalho ocorreram entre os meses de setembro e outubro de 2011 e foram realizadas pessoalmente, no site de montagem da empresa A e, nos demais casos, por telefone. Dúvidas remanescentes foram tiradas por e-mail com os responsáveis. Destaca-se que todas

Revista de Administração e Inovação, São Paulo, v. 10, n.2, p.199-218, abr./jun. 2013. 
as empresas entrevistadas foram fundadas no Brasil e apenas a empresa A exporta para outros países, como a Nova Zelândia e a Argentina. Além das entrevistas, caracterizadas como fonte primária de coleta de dados, foram analisadas a home page da internet, materiais impressos e toda a estrutura física de cada uma dessas empresas. Foi utilizado um questionário com questões semiestruturadas e depois realizada uma análise cruzada de dados. A tabela 1 apresentada no tópico 4, Resultados e Discussão, mostra detalhadamente os cargos dos entrevistados.

\section{ESTUDO DE CASO MÚLTIPLO - RESULTADOS E DISCUSSÃO}

Todas as empresas que fazem parte do estudo são associadas à Associação Brasileira do Veículo Elétrico [ABVE], que é uma associação civil de direito privado e sem fins econômicos. Tem como missão "promover a ampla utilização de veículos elétricos no país, para tornar o transporte de pessoas e cargas mais limpo e eficiente, em benefício do bem estar da população, do meio ambiente e do conjunto de seus associados" (ABVE, 2011).

Uma característica verificada foi que os sócios fundadores das empresas B, C e D eram executivos de grandes empresas multinacionais, ocupavam altos cargos dentro das organizações e tiveram vivência de trabalho em outros países. Dessas três empresas, apenas uma realizou estudo de mercado analisando potencial de consumo baseado no mercado de moto e bicicleta e estabelecendo uma comparação com cenário do setor de energia brasileiro. As demais não realizaram estudo de mercado e iniciaram suas atividades apenas por acreditar no produto e imaginar que há espaço nesse segmento no Brasil. No caso da empresa A, os sócios atuam há mais de cem anos no ramo de transportes e no caso da empresa E, os sócios atuam há mais de 50 nos setores mecânico, de energia entre outros. Nas duas últimas empresas apresentadas, A e E, verifica-se alto grau de diversificação não relacionada nos negócios (Hitt et al., 2008), em outras palavras, atuação em diversos negócios. A Erro! Fonte de referência não encontrada., apresenta algumas características das empresas pesquisadas. 
Gestão da inovação, desenvolvimento e difusão de veículos híbridos e elétricos mitigadores da poluição urbana: um estudo de caso múltiplo

Tabela 1: Caracterização das empresas do estudo

\begin{tabular}{|c|c|c|c|c|c|c|c|}
\hline Empresa & $\begin{array}{c}\text { Cargo } \\
\text { entrevistado }\end{array}$ & Classificação & Possui P\&D & $\begin{array}{l}\text { Tempo no } \\
\text { mercado }\end{array}$ & $\begin{array}{c}\text { Tipo de } \\
\text { Transporte }\end{array}$ & Estado & $\begin{array}{l}\text { Tipo de produto } \\
\text { comercializado }\end{array}$ \\
\hline A & $\begin{array}{l}\text { Gerente de } \\
\text { Contratos }\end{array}$ & Montadora & $\begin{array}{l}\text { Sim, engenheiros } \\
\text { desenvolvem adaptações } \\
\text { conforme necessidade de } \\
\text { mercado }\end{array}$ & 12 anos & Coletivo & SP & Ônibus e trólebus \\
\hline $\mathrm{B}$ & $\begin{array}{c}\text { Gerente } \\
\text { Administrati } \\
\text { vo }\end{array}$ & Montadora & $\begin{array}{l}\text { Sim, engenheiros } \\
\text { desenvolvem modelos de } \\
\text { acordo com necessidade do } \\
\text { mercado ou quando percebe } \\
\text { oportunidade de melhoria }\end{array}$ & 6 anos & Individual & $\mathrm{RN}$ & $\begin{array}{c}\text { Bicicletas e scooters } \\
\text { carrinho, prancha, } \\
\text { patinete, } \\
\text { transpaleteira, todos } \\
\text { elétricos }\end{array}$ \\
\hline $\mathrm{C}$ & Diretor & $\begin{array}{l}\text { Montadora e } \\
\text { Revendedora* }\end{array}$ & $\begin{array}{l}\text { Sim, empresa pequena, o } \\
\text { dono desenvolve com um } \\
\text { engenheiro }\end{array}$ & 2,5 anos & Individual & SP & $\begin{array}{c}\text { Bicicletas e scooters } \\
\text { elétricas }\end{array}$ \\
\hline $\mathrm{D}$ & $\begin{array}{c}\text { Gerente } \\
\text { Geral }\end{array}$ & $\begin{array}{l}\text { Montadora e } \\
\text { Revendedora* }\end{array}$ & $\begin{array}{l}\text { Sim, produtos (carcaças) } \\
\text { desenvolvidos internamente }\end{array}$ & 2 anos & Individual & $\mathrm{SC}$ & $\begin{array}{c}\text { Bicicletas e scooters } \\
\text { elétricas }\end{array}$ \\
\hline $\mathrm{E}$ & Vendedor & Montadora & Não, apenas importação & $\begin{array}{l}\text { Atua na } \\
\text { reposição de } \\
\text { peças. } \\
\text { Deixou de } \\
\text { vender }\end{array}$ & Individual & SP & $\begin{array}{c}\text { Peças para bicicletas } \\
\text { e scooters elétricas }\end{array}$ \\
\hline
\end{tabular}

Fonte: Elaborado pelos autores a partir dos dados coletados

Todas as empresas pesquisadas vendem o veículo elétrico para o cliente final. No caso da empresa A, o cliente final não é o mesmo que o usuário, caracterizando uma negociação business to business, ou entre empresas. O produto comercializado nesse caso, é um veículo de grande porte (trólebus, ônibus), direcionado para transporte público, com motor híbrido que combina duas fontes de energia, no caso, motor a diesel e gerador com baterias. As demais empresas comercializam bicicletas e scooters elétricas ao usuário final e a empresa B, além desses, comercializa carrinho, prancha, patinete, transpaleteira, todos movidos à eletricidade.

As empresas A, B, C e D disseram realizar pesquisa e desenvolvimento, mas nenhuma possui um departamento formal de P\&D. Em todos os casos, existe um responsável por verificar as necessidades do mercado, inclusive, no momento a empresa D disse estar desenvolvendo um produto para um segmento específico. Nenhuma das empresas disse ter parcerias com universidades. Apenas a empresa A possui parceria com outras empresas fornecedoras e a empresa B disse já ter realizado parcerias antes, mas o produto resultante não foi para o mercado. É interessante notar, que as empresas A, B, C e D enquadram-se como montadoras, pois elas não fabricam as peças dos veículos. No caso da empresa A, o motor a diesel, o motor elétrico de tração, o gerador, as baterias, o chassi e a carroceria são adquiridos no mercado nacional e acoplados com o retificador e o controle de tração, que foram desenvolvidos pela empresa, mas são fabricados por outras organizações. No caso das empresas B, C, 
e D, elas desenvolvem os quadros da bicicleta, mas a bateria e o motor são importados da China. Dentre essas, a empresa $\mathrm{C}$ disse que a bateria é importada dos Estados Unidos por uma questão de controle de qualidade, mas a mesma é fabricada na China assim como as demais, pois não há fabricante nacional para esse tipo de bateria. Cabe destacar que o design do quadro da bicicleta interfere no desempenho do produto. Dessa forma as empresas B, C e D buscam inovar no design que pode oferecer melhor desempenho e facilitar a difusão no mercado.

Relacionado à inovação, pesquisa e desenvolvimento é importante falar sobre as baterias, que são primordiais para os veículos elétricos e híbridos e ainda não são fabricadas no Brasil. Existem dois tipos mais comuns: as de chumbo ácido e as de lítio. As de chumbo são mais baratas, no entanto mais pesadas e tem eficiência energética menor. Além disso, são altamente poluentes, pois o chumbo é um metal pesado que se não for bem manipulado, pode contaminar o solo e os lençóis freáticos. Porém, no mercado brasileiro, as baterias de chumbo ácido têm um índice de 97\% de reciclagem, visto que a sucata desse material tem alto valor agregado e quase todos os componentes tem reutilização, até o ácido pode ser usado para limpeza depois do fim da vida útil da bateria. Já as baterias de lítio são mais caras, pois são mais leves e mais eficientes. No entanto, no Brasil, essa bateria ainda não é reciclada. Algumas empresas estão iniciando esse processo, mas ainda não é suficiente para reciclar todas as baterias existentes no mercado. Nota-se que mesmo não havendo reciclagem dessa bateria no Brasil, o lítio não tem o mesmo poder destrutivo do chumbo. Ainda relacionado à bateria, é importante destacar que deve haver um forte controle sobre a fabricação, que é realizada na China, e sobre o descarte, que atualmente é controlado pelo Instituto Brasileiro do Maior Ambiente e dos Recursos Naturais Renováveis (IBAMA). Esse ponto merece destaque, pois não resolve disseminar um produto que não emite $\mathrm{CO}_{2}$ como poluente, mas contamina o solo e lençóis freáticos e em alguns casos pode ser produzido em condições análogas ao trabalho escravo.

A Erro! Fonte de referência não encontrada. especifica o público que compra esses veículos mitigadores de poluição por tipo e perfil além de mostrar a visão dos entrevistados quanto ao crescimento ou declínio do mercado. 
Tabela 2: Caracterização das empresas quanto ao mercado, tipo e perfil de cliente

\begin{tabular}{|c|c|c|c|}
\hline Empresa & $\begin{array}{l}\text { Tipo de } \\
\text { comprador }\end{array}$ & Perfil & Mercado em Ascensão ou Declínio \\
\hline A & Pessoa Jurídica & Venda sob contrato para pessoa Jurídica. & Ascensão. Aumento nas vendas \\
\hline B & $\begin{array}{l}\text { Pessoa Jurídica e } \\
\text { Física }\end{array}$ & $\begin{array}{l}\text { Linha Indústria e comércio - Pessoa Jurídica } \\
\text { Linha Acessibilidade - Pessoa Jurídica e } \\
\text { Física } \\
\text { Linha Lazer - classe A e B, sendo que } \\
\text { jovens compram para lazer e adultos como } \\
\text { opção de transporte para trabalho }\end{array}$ & $\begin{array}{l}\text { Ascensão. Aumento nas vendas. Acredita } \\
\text { que a cultura esteja mudando em virtude de } \\
\text { apelos da mídia, no entanto população } \\
\text { brasileira não é consciente como outros } \\
\text { países (Europa e China) }\end{array}$ \\
\hline $\mathrm{C}$ & Pessoa Física & $\begin{array}{l}\text { Público mais elitizado (classe A e B), que } \\
\text { tem carro, mulheres, casais jovens, } \\
\text { profissionais liberais, jornalistas, cineastas, } \\
\text { pessoas que viajam para o exterior }\end{array}$ & $\begin{array}{l}\text { Ascensão. Aumento nas vendas. } \\
\text { No passado já teve mês de ficar sem fazer } \\
\text { nenhuma venda, hoje vende ao menos uma } \\
\text { por dia. }\end{array}$ \\
\hline $\mathrm{D}$ & Pessoa Física & $\begin{array}{l}\text { Depende do estado e do porte da cidade. } \\
\text { Vende mais para classe baixa que usa como } \\
\text { meio de transporte, idoso que não consegue } \\
\text { carteira de motorista e jovens que não } \\
\text { querem pegar ônibus ou depender dos pais }\end{array}$ & $\begin{array}{l}\text { Ascensão. Problema do momento é o } \\
\text { tráfego. } 1 \text { container ( } 1.500 \text { peças - } 2 \text { meses) } \\
\text { Uma pena que governo não faz ciclovias }\end{array}$ \\
\hline E & Pessoa Física & Não atua mais no mercado & O resultado não foi como esperado. \\
\hline
\end{tabular}

Fonte: Elaborado pelos autores a partir dos dados coletados.

Percebe-se que essas empresas, com a exceção da E que está no mercado para reposição de peças devido a lei que obriga fornecer peças de reposição por três anos, acreditam que o mercado no qual atuam é promissor. Dessas, apenas a empresa D disse atuar para o público de classe baixa como uma opção de transporte.

Dando continuidade aos resultados da pesquisa, observa-se que embora todas as empresas pesquisadas atuem fornecendo produtos mitigadores das emissões de $\mathrm{CO}_{2}$, é necessário fazer uma segmentação para poder inferir assimilações, pois o mercado, incentivos e barreiras diferem de uma empresa para outra.

A empresa A, que atua com produtos voltados para atender o transporte público de passageiros disse que há incentivos do governo nesse mercado, tanto para a montadora, quando ela pretende adquirir máquinas ou fazer expansões, quanto para as empresas operadoras, leia-se clientes, oferecendo taxas e prazos incentivadores. A principal barreira apontada é com relação à otimização do uso do combustível, que depende muito do terreno onde o veículo opera. O principal benefício apontado está relacionado à diminuição da poluição do ar devido à economia no uso de combustível fóssil. Nesse mercado, o Brasil está atrasado se comparado com outros países mais desenvolvidos visto que não há incentivos do governo para pesquisa e desenvolvimento nessa área. Uma forma para expandir o mercado desse tipo de tecnologia seria o governo aumentar o tempo de concessão para as empresas operarem no transporte público. Por lei, o veículo híbrido tem vida útil de 30 anos e esse 
tempo maior viabilizaria o investimento nesse tipo de carro. A Erro! Fonte de referência não encontrada. sintetiza esses e outros pontos identificados na entrevista.

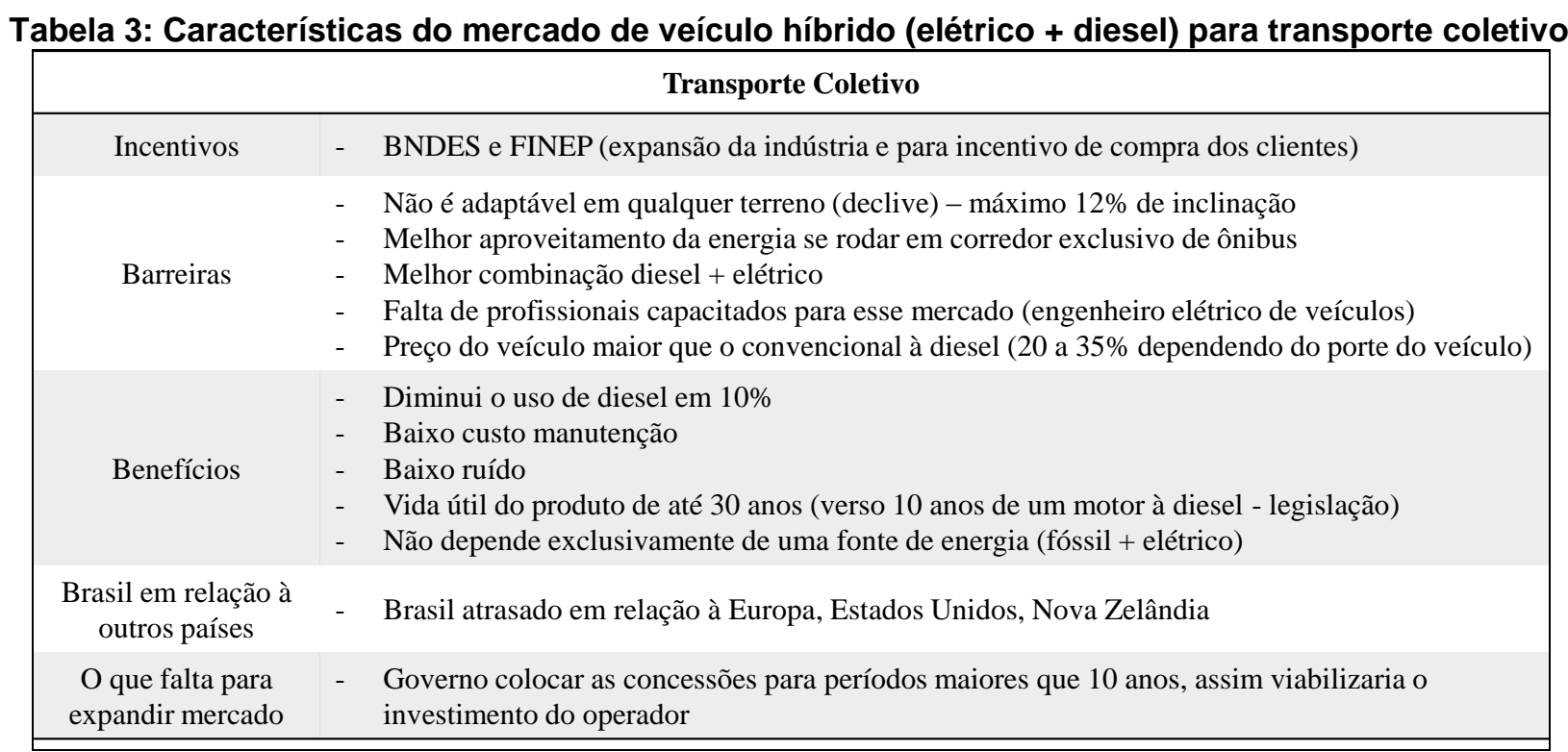

Fonte: Elaborado pelos autores a partir dos dados coletados.

No mercado de veículos para transporte individual de pessoas foi identificado que não há nenhum tipo de incentivo por parte do governo, inclusive há barreiras para a comercialização. Um exemplo foi a proibição do uso de bicicletas elétricas na cidade de Ribeirão Preto estado de São Paulo. A resolução 315 do conselho nacional de trânsito (Contran, 2009) obriga o uso de alguns equipamentos de segurança, no entanto não exige uso de carteira de habilitação para dirigir tal veículo. Soma-se a essa resolução o artigo 129 do Denatran fala que fica a critério do prefeito da cidade a regulamentação do uso desse tipo de veículo. Como as bicicletas elétricas não possuem número de série, não há como registrá-las e emplacá-las, por isso a prefeitura proibiu o uso, o que desestimula o mercado, pois as pessoas não tem a segurança de que poderão usar a bicicleta elétrica. No entanto, há cidades que permitem o uso e como benefício verifica-se a diminuição da poluição e economia no abastecimento, pois basta colocar na tomada. Para facilitar a difusão desse produto no mercado, a empresa $\mathrm{C}$ colocou dois bicicletários, locais de carregamento das bicicletas, sendo um no shopping Iguatemi em Brasília e outro no shopping Market Place em São Paulo. Mas, mesmo com esses esforços o Brasil está atrasado nesse mercado se comparado a outros países, principalmente em relação à Europa, Estados Unidos e China. Nesse ponto cabe destacar que a forma de utilização das bicicletas elétricas no mercado Europeu é muito diferente da forma usada no mercado Chinês. Na Europa as pessoas usam por opção e o motor elétrico serve para ajudar a pedalar exigindo menos esforço do 
passageiro. No mercado Chinês, esse produto é usado em substituição do transporte para deslocamentos entre casa e trabalho. Nesse sentido, o chinês faz uso do acelerador e praticamente não pedala.

Percebe-se com esse estudo que faltam incentivos e mudança de cultura do brasileiro para aumentar a difusão desse produto. Segundo o entrevistado da empresa C, o Brasil possui hoje cerca de dez produtores e quinze importadores de veículos elétricos para transporte individual e que juntos não comercializaram mais que 5 mil unidades em 2010. Para o ano de 2011, existe uma estimativa do setor para fechar em dez mil unidades, o que representa um grande salto se comparado com o ano anterior, mas é irrisório se comparado com o mercado Chinês que é de dez milhões de bicicletas elétricas por ano. O mercado de bicicletas elétricas no Brasil se intensificou nos últimos cinco anos, embora ainda seja pequeno e, se analisarmos antes desse período, pode ser considerado inexpressivo. Estima-se que exista um mercado potencial de 6 milhões de bicicletas no Brasil, sendo 50\% para uso de transporte, $32 \%$ para uso infantil, 17\% para uso de esporte e lazer e 1\% para prática de profissional. Dentre essas, o respondente da empresa C, acredita ter mercado para 200 mil unidades de bicicletas elétricas.

Além disso, foi constatado nas respostas dos entrevistados que a falta de incentivo, que dificultam a difusão desse produto nesse mercado, pode ser atribuída à Petrobras, às montadoras e aos despachantes. Esse último está relacionado ao fato de não ser necessário licenciar e emplacar as bicicletas elétricas. A Erro! Fonte de referência não encontrada. apresenta os pontos mencionados pelos entrevistados sobre as características do mercado. 
Tabela 4: Características do mercado de veículo elétrico para transporte individual

\begin{tabular}{|c|c|}
\hline \multicolumn{2}{|r|}{ Transporte Individual } \\
\hline Incentivos & - Não recebem incentivo do governo, pelo contrário, existem leis que prejudicam \\
\hline Barreiras & $\begin{array}{l}\text { - } \quad \text { Não há investimentos em pesquisa no Brasil } \\
\text { - } \quad \text { Preço do veículo elétrico que pode custar até 3x mais que um similar da sua categoria } \\
\text { - }\end{array}$ \\
\hline Benefícios & $\begin{array}{ll}\text { - } & \text { Baixo custo de abastecimento (recarregando diariamente gasta R \$ 3,00 por mês) } \\
\text { - } & \text { Não poluem o ambiente } \\
\text { - } & \text { Acessibilidade sem depender de ônibus } \\
\text { - } & \text { Não precisa de documentos } \\
\text { - } & \text { Não precisa de carteira de habilitação } \\
\text { - } & \text { Baixo custo manutenção } \\
\text { - } & \text { Baixo ruído }\end{array}$ \\
\hline $\begin{array}{l}\text { Brasil em relação à } \\
\text { outros países }\end{array}$ & $\begin{array}{l}\text { - Brasil atrasado em relação à Europa, China e Estados Unidos, mas na frente de outros países da } \\
\text { América Latina como Argentina, Chile e Colômbia. }\end{array}$ \\
\hline $\begin{array}{l}\text { O que falta para } \\
\text { expandir mercado }\end{array}$ & $\begin{array}{ll}\text { - } & \text { Incentivos do governo } \\
\text { - } & \text { Mudança de cultura do Brasileiro }\end{array}$ \\
\hline $\begin{array}{l}\text { Quem desincentiva } \\
\text { o mercado }\end{array}$ & $\begin{array}{ll}\text { - } & \text { Governo (Petrobras) } \\
\text { - } & \text { Montadoras de motos (e de carros também) } \\
\text { - } & \text { Despachantes }\end{array}$ \\
\hline
\end{tabular}

Fonte: Elaborado pelos autores a partir dos dados coletados.

A pesquisa com as empresas permitiu identificar as principais dificuldades das empresas que trabalham com produtos inovadores e que visam diminuir a poluição e contribuir com a redução dos gases do efeito estufa.

\section{CONCLUSÕES}

Um dos principais motivos para o incentivo ao uso de veículos elétricos ou híbridos, apontado por Ribeiro e Abreu (2008), está relacionado à redução da poluição ambiental nas áreas urbanas, às instabilidades nos preços, ao instável mercado de petróleo, que acima de tudo, é um combustível fóssil e finito. No Brasil, a matriz energética para veículos automotores ainda predomina o uso de energias não renováveis. Dessa forma, ainda há muito a fazer no Brasil, pois somente no mercado da empresa 
A, voltada para transporte coletivo, verificou-se incentivos do governo. No mercado das empresas B, C, D e E, de veículos elétricos para transporte individual isso não foi identificado.

Outro ponto a ser destacado no estudo está relacionado à teoria de Francis e Bessant (1995) no qual foi notado inovação no paradigma relacionado à introdução de um produto altamente difundido no mundo, mas que aqui no Brasil ainda possui mercado pequeno em fase de expansão. Referente aos relacionamentos colaborativos para difusão das bicicletas elétricas, empresas B, C, D e E, percebe-se que apenas a empresa $\mathrm{C}$ realiza algumas ações como, por exemplo, a instalação de bicicletários em shoppings e a realização de atividades nas universidades para promover o uso desse produto junto aos jovens. As demais empresas, B, D realizam as vendas através da loja e a empresa E não possui loja física e realiza a venda de peças de reposição pelo telefone. A empresa A de transporte público possui relacionamento colaborativo com as empresas que são licenciadas pela prefeitura da cidade de São Paulo a operarem o transporte coletivo de passageiros.

Referente ao processo de inovação das empresas que fabricam e comercializam produtos que melhoram a eficiência energética e reduzem a poluição, foi observado que apenas a empresa A está na terceira fase de inovação proposta por Rothwell (1992). As empresas B, C, D ainda estão na transição da fase um para a fase dois, pois colocaram um produto no mercado sem a demanda, mas agora desenvolvem melhorias de acordo com a solicitação dos clientes. Então, assim como Moura et al (2008) percebeu-se que o desenvolvimento de novos produtos $\mathrm{P} \& \mathrm{D}$ pode ocorrer de "fora para dentro".

Não foi possível identificar claramente porque existem diferenças entre as tecnologias para veículos individuais e coletivos mencionadas no item 2.2. Embora possa estar associada ao custo versus necessidade e eficiência do motor, recomenda-se um estudo adicional para confirmar essa análise e coletar dados econômicos comparativos.

Com relação à difusão da tecnologia percebeu-se diferença se compararmos a empresa $\mathrm{A}$ com as demais. No mercado da empresa A, existem incentivos do governo e a comercialização ocorre sob encomenda. A difusão do veículo de transporte coletivo no mercado é facilitada pelos benefícios oferecidos que estão relacionados à redução do uso de diesel, baixo custo de manutenção, baixo ruído, vida útil do produto de aproximadamente trinta anos e a possibilidade de uso de mais de uma fonte de energia. As barreiras que dificultam a difusão desse produto estão relacionadas basicamente ao preço, ao relevo, que deve possuir condições específicas, e ao uso de um corredor específico e exclusivo para esse tipo de transporte. No caso das demais empresas estudadas, B, C, D e E a difusão é mais 
trabalhosa, pois além de não haver incentivo por parte do governo, existem barreiras legais com altas taxas de importação, falta de incentivo em pesquisa para melhoria dos modelos existentes, alto preço, cultura do brasileiro que ainda não está acostumado com o uso desse tipo de produto, baixa autonomia, relevo e a dependência de uma única fonte de energia para reabastecer o veículo que pode ser comprometido em épocas de apagão. No entanto, existem alguns benefícios que ajudam a difusão desse produto, como por exemplo, possuir baixo custo de abastecimento e manutenção, ser um veículo não poluente, não serem necessários documentos de registro e carteira de habilitação.

O estudo também constatou que importantes inovações ambientais, como energias mais limpas e propulsão veicular, levam tempo para serem incorporadas (Huber, 2008), nesse sentido é natural que o Brasil esteja atrasado em relação a outros países, pois esse mercado é recente. Baseado na teoria de Conway e Steward (1998) apenas a empresa A iniciou projeto de inovação ambiental por identificar uma necessidade no seu cliente.

Para finalizar, sugere-se refletir sobre alternativas que mitiguem a poluição e elas não precisam necessariamente estar relacionadas à tecnologia de transporte, assim como proposto por Rietveld (2011). Existem situações que não há como evitar o deslocamento de pessoas como, por exemplo, ronda de polícia e seguranças, grupo de staff que irão trabalhar na copa do mundo, entre outros. Nesses casos, a tecnologia apresentada nesse trabalho é muito interessante, tanto do ponto de vista de transporte individual como coletivo. Por fim, foi verificado com esse estudo que as redes de difusão da inovação não estão relacionadas ao processo de inovação e sim ao modelo de negócio no qual elas atuam. 


\section{REFERÊNCIAS}

ABVE - Associação Brasileira do Veículo Elétrico. Disponível em: http://www.abve.org.br/. Acesso em: $11 / 08 / 2011$.

Banoma, T.V. (1985). Case research in Marketing: Opportunities, Problems, and a Process. Journal of Marketing Research. 12 (1), 199-208.

BRASIL, Contran - Conselho Nacional de Trânsito. Resolução no 315, oito de maio de 2009.

Disponível em: http://www.denatran.gov.br/download/Resolucoes/RESOLUCAO_CONTRAN_315_09.pdf. Acesso em: 26 de setembro de 2011

BRASIL, Denatran - Departamento Nacional de Trânsito. Capítulo XI do Registro de Veículos, artigo 129. Disponível em: http://www.pr.gov.br/mtm/legislacao/ctb/cap_xi.htm. Acesso em: 26 de setembro de 2011

Consoli, M.A. (2008). Uma discussão sobre a utilização do estudo de caso como métodos de pesquisa em ciências gerenciais. In: XXXII Encontro da ANPAD, Rio de Janeiro.

Conway, S., \& Steward, F. (1998) Networks and Interfaces in environmental innovation: a Comparative Study in the UK and Germany. The Journal of High Technology Management Research, 9 (2), 239-253.

Elkington, J. (1997). Cannibal with Forks: The Triple Bottom Line of 21st Century Business. Canada: NSP New Society Publishers.

EPE - Empresa de Pesquisa Energética. Balanço Energético Nacional, BEM. Ano base 2010, resultados preliminares. Ministério de Minas e Energia, Rio de Janeiro, 2011.

Francis, D., \& Bessant, J. (2005). Targeting innovation and implications for capability development. Technovation. 25 (1), 171-183.

Gouveia, N. et al. (2003). Poluição do ar e efeitos na saúde nas populações de duas grande metrópoles brasileiras. Epidemiologia e Serviços da Saúde. 12 (1), 29-40.

Gulati, R. (1998). Alliances and Networks. Strategic Marketing Journal, 19 (1), 293-317.

GVCES; PNUMA. (2011). Financiamentos Públicos e Mudança do Clima: Análise das estratégias e práticas de bancos públicos e Fundos Constitucionais Brasileiros na Gestão da Mudança do Clima. Centro de estudos em Sustentabilidade da Fundação Getúlio Vargas (GVCES) e Programa das Nações Unidas para o Meio Ambiente PNUMA 65 p. 
Hitt, M., Ireland, R. D., \& Hoskisson, R. E. (2008). Administração Estratégica: competitividade e globalização. Tradução All Tasks, título original: Strategic Management: competitiveness and globalization. 2.ed. São Paulo: Engage Learning.

Huber, J. (2008). Pionner countries and the global diffusion of environmental innovations: theses from the viewpoint of ecological modernization theory. Global Environment Change. 18 (1), 360-367.

IPCC. Climate Change (2007). Synthesis Report. Contribution Of Working Groups I, II and III to the Fourth Assessment Report of the Intergovernmental Panel on Climate Change [Core Writing Team, Pachauri, R.K. and Reisinger, A. (eds.). IPCC, Geneva Switzerland, 104 p.

Jacob, K. et al. (2001). Lead Markets for Environmental Innovations. ZEW Economic Studies, Heidelberg: Physica.

Kumaresan, J, Narain, J. P., \& Sathiakumar, N. (2011). Climate change and health in South East Asia. International Journal of Climate Change Strategies and Management. 3 (2), 200-208.

Mayer, H. (1999). Air pollution in cities. Atmospheric Environment. Oxford, 33 (1), 4029 - 4037.

Moura, G. L., Carmo, M., Calia, R.C., \& Façanha, S. L. O. (2008). Aprendizado em redes e processo de inovação dentro de uma empresa: O caso Mextra. RAE - Eletrônica., 7 (1).

Neely, A., \& Hii, J. (1998). Innovation and Business Performance: a Literature Review. The judge Institute of Management Studies, University of Cambridge. $49 \mathrm{p}$.

Neves, M. F. (2007). Strategic Marketing plans and collaborative networks. Marketing Intelligence \& Planning. 25 (2), 175-192.

Ribeiro, S. K., \& Abreu, A. A. (2008). Brazilian Transport Initiatives with GHG Reductions as a cobenefit. Climate Policy. 8 (1), 220-240.

Rietveld, P. (2011). Telework and transition to lower energy use in transport: on the relevance of rebound effects. Environmental Innovations and Societal Transitions. 1 (1), 146-151.

Rogers, E.M., \& Schoemaker, F.F. (1971). Communication of Innovations: A cross cultural Approach. New York: Free Press.

Rothwell, R. (1992). Successful industrial innovation: critical factors for the 1990's. $R \& D$ Management. 22(1), 221-239.

Voss, C., Tsikriktsis, N., \& Frohlich, M. (2002). Case research in operations and management. International Journal of Operations \& Production Management, 22 (2), 195-219.

WHO, World Health Organization. (2001). Disponível em http://www.who.int/topics/climate/en/. Acesso em 25 de julho de 2011.

WHO, World Health Organization (2008). Protecting Health for Climate Change - Summary of issues paper.

Revista de Administração e Inovação, São Paulo, v. 10, n.2, p. 199-218, abr./jun. 2013. 
WHO, World Health Organization (2011). Protecting Health from Climate Change - Global Research Priorities. Disponível em: http://whqlibdoc.who.int/publications/2009/9789241598187_eng.pdf . Acesso em: 25 de julho de 2011.

Yalabic, B., \& Fairchild, R. J. (2011). Customer, regulatory, and competitive pressure as a driver of environmental innovation. International Journal of Production Economics. 131 (1) , 519-527.

Yin, R. K. (2010). Estudo de Caso: Planejamento e Métodos. 4. ed. Porto Alegre: Bookman.

\section{MANAGEMENT OF INNOVATION, DEVELOPMENT AND DIFFUSION OF HYBRIC AND ELECTRIC VEHICLES FOR MITIGATING URBAN POLLUTION: A MULTIPLE CASE STUDY}

Studies have indicated that the increased use of fossil fuels as well as the use of lands raise the level of carbon dioxide (CO2), thus changing the ecosystem and contributing to global warming as a result. In this sense, it is needed to encourage research and disseminate innovative products aimed at improving the energetic efficiency and mitigating the emission of greenhouse gases involved in the global warming. For doing so, a multiple case study involving five Brazilian motor vehicle manufacturers and distributors was developed in order to understand how innovation, development, and diffusion of pollution mitigation products occur in the segment of hybrid and electric vehicles for individual and collective transportation. According to the findings of our study, one can note that hybrid and electric vehicle market for either individual or collective purposes is still small in Brazil, although this market is in an expansion phase. Of the companies studied, only one developed a product aimed at meeting these market needs. The other companies have traded their products and now are migrating towards a new way of meeting their clients' needs by developing adaptations in order to diffuse their products into the Brazilian market.

Key-words: $\mathrm{CO} 2$ mitigation, electric vehicles, hybrid vehicles, innovation diffusion, innovation management.

Data do recebimento do artigo: 08/12/2012

Data do aceite de publicação: 15/05/2013

Revista de Administração e Inovação, São Paulo, v. 10, n.2, p.199-218, abr./jun. 2013. 